\title{
OBSERVACIONES ADICIONALES SOBRE ICHTHYOCEPHALUS VICTORI GARCÍA ET FONTENLA, 2002 (NEMATODA: ICHTHYOCEPHALIDAE) DE PUERTO RICO
}

\section{Adittional observations on Ichthyocephalus victori García \& Fontenla, 2002 (Nematoda: Ichthyocephalidae) from Puerto Rico}

\author{
Nayla García Rodríguez ${ }^{1}$, Jans Morffe Rodríguez ${ }^{1}$ y Koichi Hasegawa² \\ 'Instituto de Ecología y Sistemática, Carretera Varona 11835 e/ Oriente y Lindero, La Habana 19, CP 11900, \\ Calabazar, Boyeros, La Habana, Cuba.nayla@ecologia.cu, jans@ecologia.cu. \\ ${ }^{2}$ Department of Environmental Biology, College of Bioscience \& Biotechnology, Chubu University, 1200 \\ Matsumoto, Kasugai, Aichi 487-8501, Japan. koichihasegawa@isc.chubu.ac.jp.
}

\section{RESUMEN}

Se ofrecen datos adicionales y detallados sobre la cutícula, estructura y extensión de las microtricas, extremo cefálico, disposición de las papilas copulatorias precloacales y espículas de los ejemplares machos de Ichthyocephalus victori García et Fontenla, 2002 (Nematoda: Ichthyocephalidae), mediante imágenes de Microscopía Electrónica de Barrido (MEB). Dichos datos se comparan con I. cubensis Spiridonov, 1989 e I. anadenoboli Van Waerebeke, Adamson et Kermarrec, 1984, únicas especies del género donde hay estudios previos con MEB.

Palabras clave: Ichthyocephalus, Ichthyocephalidae, Diplopoda, Puerto Rico, Microscopía Electrónica de Barrido.

\section{ABSTRACT}

Based on SEM studies, additional data on the cuticle, structure and extension of the microtricha, cephalic end, arrangement of the pre-cloacal copulatory papillae and spicules of the males of Ichthyocephalus victori García \& Fontenla, 2002 (Nematoda: Ichthyocephalidae) are provided. Such data are compared with I. cubensis Spiridonov, 1989 and I. anadenoboli Van Waerebeke, Adamson \& Kermarrec, 1984; the only species with previous SEM studies.

Keywords: Ichthyocephalus, Ichthyocephalidae, Diplopoda, Puerto Rico, Scanning Electronic Microscopy.

La especie Ichthyocephalus victori García et Fontenla, 2002 (Nematoda: Ichthyocephalidae), fue descrita como parásita en especímenes de Rhinocricus parcus Karsch, 1881 (Diplopoda: Rhinocricidae), colectados en Cambalache, Puerto Rico. Por el mal estado del material disponible en la ocasión, la descripción se hizo en base a solo tres ejemplares machos del nemátodo, mientras que de las hembras solo fue referida la presencia del divertículo vaginal (García y Fontenla, 2002). García y Morffe (2015), describen las hembras de esta especie y redescriben los machos, a partir de ejemplares de I. victori, en idéntico hospedante pero provenientes de otra localidad de Puerto Rico: Bosque Estatal de Susúa, Sabana Grande. En este trabajo se aclara la pertenencia de I. victori al grupo anadenoboli (Hunt, 1994; 1999) caracterizado por la ausencia de diferencias notables en la talla de ambos sexos, hembras con divertículo vaginal y machos con espículas desiguales, además del patrón papilar supernumerario y asimétrico. 
De Ichthyocephalus se conocen imágenes de Microscopía Electrónica de Barrido (MEB) de solo dos especies, I. cubensis e I. anadenoboli (Hunt, 1999), con descripciones precisas acerca de la cutícula, estructura y extensión de las microtricas, extremo cefálico, espículas y patrón papilar. En este trabajo se complementa la descripción de los machos I. victori con detalles sobre estas estructuras.

Se recolectaron manualmente, bajo hojarasca, tres ejemplares de Rhinocricus parcus Karsch, 1881 (Diplopoda: Rhinocricidae) en el Bosque Estatal Susúa, Sabana Grande, Puerto Rico. Los diplópodos se sacrificaron por decapitación y sus intestinos se extrajeron inmediatamente mediante cortes en los últimos segmentos posteriores. Los mismos se fijaron en alcohol isopropílico al 70\% hasta el momento de ser procesados.

Para su estudio por MEB, varios ejemplares machos se fijaron posteriormente durante la noche en glutaraldehído al $2 \%$, disuelto en buffer fosfato $(\mathrm{pH}=6)$ al $0.1 \mathrm{M}$ y durante una hora en tetróxido de osmio al 2\%. Luego, se deshidrataron en una serie de etanol de concentración creciente $(30 \%, 50 \%, 70 \%, 90 \%, 95 \%, 100 \% \times 2,30$ min en cada uno) (Morffe y Hasegawa, 2017). Previo al paso de secado por congelación (en un secador ES-2030; Hitachi, Japón) los nemátodos fueron transferidos a una mezcla de etanol absoluto/t-butanol $(1: 1 \mathrm{v} / \mathrm{v})$ y después a t-butanol puro (30 min en cada paso). Los ejemplares se montaron en cinta adhesiva de aluminio y se cubrieron de oro. Las fotografías se realizaron en un microscopio electrónico de barrido JSM-6510LA; JEOL, Japón, con un voltaje de aceleración de 15 kV.

\section{TAXONOMÍA}

Familia ICHTHYOCEPHALIDAE Travassos et Kloss, 1958

Ichthyocephalus Artigas, 1926

Ichthyocephalus victori García et Fontenla, 2002

Figura 1, A-H

Ichthyocephalus victori García et Fontenla, 2002: 3-4, Fig. 2, A-B.

Ichthyocephalus victori García et Fontenla, 2002: 105-110, Fig. 1, A-J, redescripción.

Descripción. Machos. Cutícula con estrías transversales estrechas, desde el extremo cefálico, desde el margen de las mandíbulas hasta casi el extremo de la cola, donde se hacen más tenues, hasta desaparecer completamente. Microtricas con forma de triángulos isósceles muy alargados, imbricadas y alternas, dispuestas en el margen posterior de las estrías, unidas en su base. Más largas y más densas en la región dorsal del extremo cefálico, donde se curvan hacia el extremo anterior, dando una apariencia de rizos afelpados (Fig. 1B), haciéndose mucho más cortas y delgadas hacia la región posterior, hasta desaparecer con las estrías en el extremo de la cola.

Cápsula cefálica lisa, comprimida dorsoventralmente. Apertura oral lateralmente orientada, en forma de hendedura, dividiendo la región cefálica en una mandíbula dorsal y otra ventral (Fig. 1A). Cuatro papilas cefálicas cónicas, pequeñas y cortas, dos dorsales y dos ventrales, las primeras ligeramente más separadas entre sí que las segundas. Anfidios en forma de poro, con un grueso reborde cuticular, ubicados en el ángulo de las dos mandíbulas hacia la región ventral. Proyección cuticular digitiforme, algo alargada, ubicada en el margen de las dos mandíbulas, por delante de los anfidios (Fig. 1C). Piezas bucales en número de tres, una dorsal y dos subventrales. Dichas piezas bucales presentan numerosos dentículos triangulares y alargados, dispuestos en líneas apretadas y densas, imbricados y alternos (Fig. 1D). 

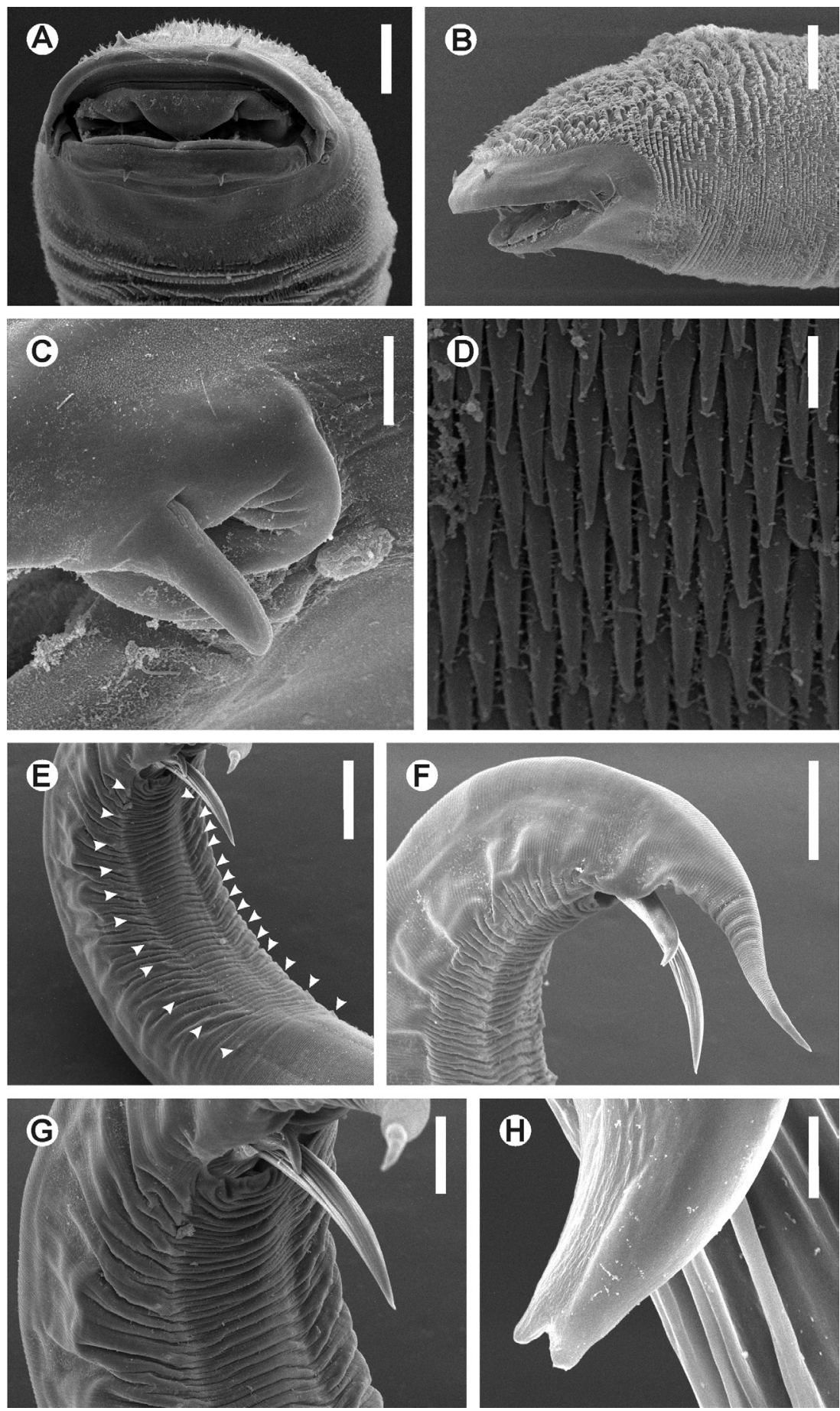

Figura 1. Ichthyocephalus victori García et Fontenla, 2002. Macho, imágenes de Microscopía Electrónica de Barrido. A, extremo cefálico, en face. B, extremo cefálico, vista lateral. C, proyección cuticular digitiforme y anfidio en el ángulo de las mandíbulas. $\mathrm{D}$, dentículos de la pieza bucal dorsal. E, región precloacal, vista ventrolateral (las puntas de flecha indican la posición de las papilas precloacales). F, región caudal, vista lateral. G, extremo distal de la espícula derecha. H, detalle del extremo distal de la espícula izquierda. Líneas de escala: A, B, G, $50 \mu \mathrm{m} ; \mathrm{C}, 10 \mu \mathrm{m} ; \mathrm{D}, 1 \mu \mathrm{m} ; \mathrm{E}, \mathrm{F}, 100 \mu \mathrm{m} ; \mathrm{H}, 5 \mu \mathrm{m}$. 
Cola subulada, casi cónica, arqueada hacia la región ventral (Fig. 1F). Región ventral donde se ubican las papilas notablemente rugosa, con la cutícula formando plegamientos transversales que agrupan varias estrías. Papilas pequeñas, redondeadas, poco sobresalientes, muy ligeramente cónicas en vista lateral. Las papilas precloacales se disponen en un patrón supernumerario y asimétrico, en número de 11 a 13 papilas en el lado izquierdo y 14 en el derecho en los ejemplares observados (Fig. 1E). Las papilas precloacales más anteriores están menos desarrolladas. Espícula derecha terminada en punta, curvada ventralmente hacia el extremo, con estrías longitudinales muy bien marcadas (Fig. 1G). Espícula izquierda también curvada, terminada en dos lóbulos redondeados, con estrías irregularmente reticuladas en su región ventral (Fig. 1H).

De las especies del grupo anadenoboli se conocen imágenes de MEB de I. cubensis Spiridonov, 1989 e I. anadenoboli Van Waerebeke, Adamson et Kermarrec, 1984 (García y Morffe, 2015; Hunt, 1999; Spiridonov, 1989; Van Waerebeke et al., 1984). En todas ellas se aprecia el extremo cefálico dorsoventralmente comprimido, con la apertura oral lateralmente orientada, dando la apariencia característica del género, a la cual deben su nombre. También se aprecian las cuatro papilas cefálicas, dos dorsales y dos ventrales, las primeras algo más separadas entre sí que las segundas. Las tres especies presentan una estructura digitiforme, a manera de espuela, en la unión de las mandíbulas y por delante de la apertura de los anfidios, no registradas para otras especies del género (Hunt, 1999).

En las tres especies, las estrías y microtricas se extienden desde el margen de la cápsula cefálica hasta casi el extremo de la cola en ambos sexos, aunque en el caso de I. victori solo se tienen imágenes de los machos. Las microtricas están dispuestas en el margen posterior de las estrías y son más densas y largas en la región dorsal del extremo cefálico. Hacia el extremo caudal dichas microtricas se vuelven cortas y espaciadas. La apariencia densamente rizada de las microtricas en la región dorsal del extremo cefálico de I. cubensis, referida por Hunt (1999), se debe a su curvatura hacia atrás y a su disposición alterna y superpuesta en cada una de las estrías, también apreciable en I. victori. En el caso de I. anadenoboli, aunque las microtricas se disponen de forma similar, no se aprecia la apariencia rizada por la menor longitud de estas. I. victori ocupa una posición intermedia por la longitud de sus microtricas $(17-20 \mu \mathrm{m})$ entre I. anadenoboli $(2-3 \mu \mathrm{m})$, mucho más cortas e I. cubensis mucho más largas $(23-25 \mu \mathrm{m})$.

La marcada rugosidad del área ventral donde se ubican las papilas en I. victori no se observa en las fotos ni se refiere en la descripción de las otras dos especies, aunque pudiera deberse a la contracción de la cutícula en esta área por efectos de la fijación y el montaje. García y Morffe (2015), en la redescripción de los machos de I. victori, mencionan la presencia de papilas copulatorias precloacales supernumerarias y asimétricas, en número de 10 a 11 en el lado izquierdo y de 9 a 13 en el lado derecho. En los ejemplares estudiados por MEB el número de papilas precloacales está en el rango mencionado por dichos autores, aunque un ejemplar presentó 13 papilas en el lado izquierdo y otro 14 papilas en el lado derecho. En cuanto al número de papilas precloacales, I. victori también ocupa una posición intermedia entre I. anadenoboli ( 7 a 10 papilas en el lado izquierdo y 6 a 7 en el derecho) e I. cubensis (11 a 13 papilas en el lado izquierdo y 9 a 14 en el derecho). 
Hunt (1999) refiere la presencia de estrías en la espícula derecha y punteaduras en la región ventral de la izquierda en I. cubensis, pero no hace mención explícita de estas características en I. anadenoboli, tampoco referidas por Van Waerebeke et al. (1984). En I. victori se aprecian estrías longitudinales en la espícula derecha y estrías irregularmente reticuladas, no punteaduras, en la parte ventral de la izquierda. La cola es cónica a subulada en los machos de las tres especies con el extremo ligeramente arqueado hacia la región ventral, carácter del que no se ofrecen imágenes ni aparece referido en las descripciones pero si es apreciable en los dibujos a línea. La variación en el grado de curvatura pudiera ser también efecto de los procesos de fijación y montaje como en el caso de la rugosidad en la región ventral donde se ubican las papilas.

\section{AGRADECIMIENTOS}

Al Dr. Luis F. de Armas, del Instituto de Ecología y Sistemática y a Antonio Pérez-Asso por la recolecta de los hospederos estudiados. El financiamiento para Microscopía Electrónica de Barrido fue otorgado al segundo autor por la Japanese Society for the Promotion of Science (JSPS), Long Term Fellowship (ID No. L16566). Estos resultados están inscritos en el proyecto "Colecciones Zoológicas, su conservación y Manejo III" del Programa Nacional de Ciencia y Técnica "Uso sostenible de los Componentes de la diversidad biológica en Cuba", Ministerio de Ciencia, Tecnología y Medio Ambiente, Cuba.

\section{LITERATURA CITADA}

García, N. y J. L. Fontenla. 2002. New species of nematodes (Nematoda: Rhigonematida) associated with Rhinocricus parcus (Diplopoda) from Puerto Rico. Solenodon, 2: 1-5.

García, N. y J. Morffe. 2015. Redescripción de Ichthyocephalus victori García et Fontenla, 2002 (Nematoda: Icthyocephalidae) de Puerto Rico. Novitates Caribaea, 8: 104-111.

Hunt, D. J. 1994. A synopsis of the Ichthyocephalidae (Nematoda: Rhigonematida) with description of Ichthyocephaloides xesmostoma sp. n. in a diplopod from Papua New Guinea. Afro-Asian Journal of Nematology, 4 (1): 104-108.

Hunt, D. J. 1999. The Ichthyocephalidae (Nematoda: Rhigonematida). Characterisation and morphology with proposal of two new species of Ichthyocephaloides and additional data on Ichthyocephalus cubensis and I. anadenoboli. International Journal of Nematology, 9 (2): 101-118.

Morffe, J.y K. Hasegawa. 2017. Rhigonema naylae n. sp. (Rhigonematomorpha: Rhigonematidae)a new parasitic nematode from a Japanese polydesmid millipede (Polydesmida: Xystodesmidae). Zootaxa, 4269: 277-286.

Spiridonov, S. E. 1989. New species of Rhigonematida (Nematoda) from the Cuban spirobolid Rhinocricus sp. (Diplopoda). Folia Parasitologica, 36: 71-82.

Van Waerebeke, D., M. L. Adamson y A. Kermarrec. 1984. Spermiogenese et function du sac vaginal chez Ichthyocephalus anadenoboli n. sp. (Rhigonematidae; Nematoda), parasite d'Anadenobolus politus (Porat) (Rhinocricidae; Diplopoda) en Guadeloupe. Annales de Parasitologie Humaine et Comparée, 59: 101-109.

[Recibido: 07 de mayo, 2018. Aceptado para publicación: 12 de junio, 2018] 